\title{
ESTRATEGIA DE INTEGRACIÓN DEL PEQUEÑO AGRICULTOR A LA CADENA DE EXPORTACIONES*
}

\author{
Pedro Barrientos Felipa** \\ https://doi.org/10.22395/seec.v22n51a5
}

\section{RESUMEN}

La agricultura orientada a la exportación en Perú tiene un desarrollo significativo, lo cual genera expectativas alentadoras para la economía. En este contexto debe integrarse al pequeño agricultor, motivo por el cual el artículo tiene por objetivo exponer lo que está ocurriendo con el pequeño agricultor y las acciones necesarias para su integración a la cadena de exportaciones. Se revisó bibliografía relacionada con la agricultura peruana que se seleccionó considerando lo que ocurre en otros países latinoamericanos que también atraviesan por unos procesos similares -implantación de nuevos productos e ingreso a nuevos mercados extranjeros-para obtener información primaria se entrevistó a expertos y se aplicó una encuesta a pequeños agricultores del distrito de Lunahuaná, cuyos resultados se incluyen en los anexos respectivos y se exponen las expectativas que tienen los pequeños agricultores en este proceso.

\section{PALABRAS CLAVE}

Asociatividad; cadena de valor; exportaciones agrícolas; integración; pequeño agricultor

\section{CLASIFICACIÓN JEL}

Q17, Q18

\section{CONTENIDO}

Introducción; 1. Integración del pequeño agricultor a la cadena de exportaciones; 2. Situación actual de la pequeña agricultura y los grandes exportadores; 3. La pequeña agricultura y el papel del Estado; 4. Conclusiones; Bibliografía.

Este artículo es resultado de la investigación que se realizó a través del Grupo de Investigación Ecoagrox y que se titula Las acciones necesarias para integrar al pequeño agricultor a la cadena de exportaciones. La investigación fue auspiciada por el Instituto de Investigaciones Económicas y financiada por el Vicerrectorado de Investigación y Posgrado de la Universidad Nacional Mayor de San Marcos.

* Economista, Universidad Ricardo Palma, Lima, Perú. Magíster en Administración, Universidad del Pacífico, Lima, Perú. Doctor en Administración de Negocios Globales, Universidad Ricardo Palma, Lima, Perú. Vicedecano de Investigación y Posgrado, profesor principal y miembro del Instituto de Investigaciones Económicas, Facultad de Ciencias Económicas, Universidad Nacional Mayor de San Marcos, Lima, Perú. Correo electrónico: pbarrientosf@unmsm.edu.pe 


\title{
SMALL FARMER'S INTEGRATION STRATEGY IN THE EXPORTING CHAIN
}

\begin{abstract}
Export-oriented agriculture in Peru has significant development, which generates encouraging expectations for economy. In this context, small farmers must be integrated, which is why the article aims to expose what is happening with small farmers and necessary actions for its integration into the exporting chain. Bibliography related to Peruvian agriculture was selected, considering what is happening in other Latin American countries that are also going through similar processes -implementation of new products and entry to new foreign markets-. To obtain primary source information, experts were interviewed and a survey to small farmers in the district of Lunahuaná was applied, results of both are included in the respective annexes; expectations that small farmers have in this process are also presented.
\end{abstract}

\section{KEYWORDS}

Associativity; value chain; agricultural exports; integration; small farmer

\section{JEL CLASSIFICATION}

Q17, Q18

\section{CONTENTS}

Introduction; 1. Small farmer's Integration to the exporting chain; 2. Current situation of small agriculture and large exporters; 3. Small-scale agriculture and the State's role; 4. Conclusions; Bibliography.

\section{ESTRATÉGIA DE INTEGRAÇÃO DO PEQUENO AGRICULTOR À CADEIA DE EXPORTAÇÕES}

\section{RESUMO}

A agricultura dirigida à exportação no Peru tem um desenvolvimento significativo, o que gera expectativas alentadoras para a economia. Nesse contexto, deve ser integrada ao pequeno agricultor, razão pela qual este artigo tem o objetivo de expor o que está acontecendo com o pequeno agricultor e com as ações necessárias para sua integração à cadeia de exportações. Foi revisada bibliografia relacionada com a agricultura peruana que foi selecionada tendo em vista o que ocorre em outros países latino-americanos que também passam por processos similares: implantação de novos produtos e ingresso a novos mercados estrangeiros. Para obter informação primária, foram entrevistados especialistas, aplicado um questionário a pequenos agricultores de Lunahuaná, cujos resultados são incluídos nos anexos respectivos, e expostas as expectativas que os pequenos agricultores têm nesse processo.

\section{PALAVRAS-CHAVE}

Associatividade; cadeia de valor; exportações agrícolas; integração; pequeno agricultor.

\section{CLASSIFICAÇÃO JEL}

\author{
Q17, Q18
}

\section{CONTEÚDO}

Introdução; 1. Integração do pequeno agricultor à cadeia de exportações; 2. Situação atual da pequena agricultura e dos grandes exportadores; 3 . A pequena agricultura e o papel do Estado; 4. Conclusões; Bibliografia. 


\section{INTRODUCCIÓN}

La agricultura orientada a la exportación en Perú tiene un desarrollo significativo, lo cual genera expectativas alentadoras para la economía. En este contexto debe integrarse al pequeño agricultor mediante esfuerzos conjuntos del Estado y de los grandes exportadores. Este artículo tiene por objetivo exponer lo que está ocurriendo con el pequeño agricultor y las acciones necesarias para su integración a la cadena de exportaciones. Para tal caso, se utiliza como insumo la revisión de diversos documentos relacionados con la agricultura peruana considerando lo que ocurre en otros países latinoamericanos que atraviesan por un proceso similar.

La revisión de la literatura se complementa con la inclusión de los resultados de la investigación Las acciones necesarias para integrar al pequeño agricultor a la cadena de exportaciones, cuyos resultados también son consecuencia de haber realizado una encuesta a los pequeños agricultores del distrito de Lunahuaná (Cañete, Lima). Se realizaron entrevistas a expertos en el tema con la finalidad de tener respuestas más precisas acerca del tema, para ello se aplicó un cuestionario no estructurado (ver anexo 1).

El complemento es un estudio tipo descriptivo con la finalidad de cuantificar de mejor manera el fenómeno. Por tal motivo, se elaboró un cuestionario (ver anexo 2) que fue aplicado a los agricultores del distrito de Lunahuaná (Cañete). Se adjuntan los resultados de la encuesta (anexo 3) a los pequeños agricultores del distrito, con la cual se buscaba identificar las posibilidades y expectativas de los pequeños agricultores en este importante valle del Perú. La ciudad se ubica al sur de la ciudad de Lima, a aproximadamente 180 kilómetros. Debido a la dispersión geográfica de los pequeños agricultores se logró realizar 130 contactos efectivos. La producción agrícola en este valle se basa en el cultivo de: uvas para licor (pisco, vino), pacae, manzana Israel, pepino, níspero, granada y paltas.

\section{INTEGRACIÓN DEL PEQUEÑO AGRICULTOR A LA CADENA DE EXPORTACIONES}

La producción agraria en el Perú presenta cambios significativo en sus montos de producción si se considera que en el año 2000 se cosecharon 2.755.261 ha y el año 2013 se llega a la cantidad de 3.334.561 ha. En lo que corresponde al área sembrada, para el mismo período, se pasó del 1.670 .905 ha a 1.901 .382 ha. Su participación relativa en la composición del producto interno bruto (PIB), en el período de análisis, disminuyó de 6,97 \% del PIB en el año 2000 a 5,24 \% en el 2016, decrecimiento que se inicia en el año 2007, toda vez que en el 2006 logró una tasa de participación de 6,27\%. En lo que corresponde a la inversión extranjera los mejores años son 2014 y 2015, tal como puede observarse en la tabla 1 . 
Tabla 1. Principales indicadores del sector agrario, 2000 -2015

\begin{tabular}{|c|c|c|c|c|c|c|}
\hline \multirow{2}{*}{ Año } & \multirow{2}{*}{$\begin{array}{c}\text { Superficie } \\
\text { cosechada (ha) }\end{array}$} & \multirow{2}{*}{$\begin{array}{l}\text { Valor de la } \\
\text { producción } \\
\text { agrícola } \\
\text { (millones de } \\
\text { S/2007) }\end{array}$} & \multicolumn{2}{|c|}{$\begin{array}{c}\text { Valor agregado de } \\
\text { agricultura }\end{array}$} & \multirow{2}{*}{$\begin{array}{c}\text { Superficie } \\
\text { sembrada (ha) }\end{array}$} & \multirow{2}{*}{$\begin{array}{c}\text { Inversión } \\
\text { extranjera } \\
\text { (millones } \\
\text { USD) }\end{array}$} \\
\hline & & & $\begin{array}{c}\text { Millones de S/ } \\
2007\end{array}$ & $\begin{array}{l}\text { Porcentaje del } \\
\text { PBI total }\end{array}$ & & \\
\hline 2000 & 2.755 .261 & 11.488 & 15.496 & 6,97 & 1.670 .905 & 44,40 \\
\hline 2001 & 2.652 .558 & 11.494 & 15.374 & 6,88 & 1.655 .109 & 44,40 \\
\hline 2002 & 2.699 .874 & 12.250 & 16.152 & 6,85 & 1.655 .987 & 44,40 \\
\hline 2003 & 2.700 .585 & 12.341 & 16.472 & 6,71 & 1.552 .680 & 44,40 \\
\hline 2004 & 2.590 .195 & 12.292 & 16.391 & 6,36 & 1.684 .587 & 44,40 \\
\hline 2005 & 2.815 .704 & 13.229 & 16.948 & 6,19 & 1.712 .227 & 44,40 \\
\hline 2006 & 2.869 .499 & 14.468 & 18.462 & 6,27 & 1.740 .102 & 44,40 \\
\hline 2007 & 2.919 .240 & 14.522 & 19.074 & 5,97 & 1.765 .702 & 44,83 \\
\hline 2008 & 3.035 .605 & 15.935 & 20.600 & 5,90 & 1.798 .009 & 45,66 \\
\hline 2009 & 3.129 .205 & 15.931 & 20.784 & 5,89 & 1.772 .700 & 45,66 \\
\hline 2010 & 3.113 .965 & 16.353 & 21.656 & 5,67 & 1.733 .744 & 45,66 \\
\hline 2011 & 3.089 .042 & 17.004 & 22.517 & 5,54 & 1.929 .346 & 45,66 \\
\hline 2012 & 3.240 .582 & 18.475 & 23.944 & 5,55 & 1.940 .074 & 45,66 \\
\hline 2013 & 3.334 .561 & 18.639 & 24.262 & 5,31 & 1.901 .382 & 45,66 \\
\hline 2014 & $\ldots$ & 18.791 & 24.609 & 5,26 & 1.937 .783 & 70,97 \\
\hline 2015 & $\ldots$ & 19.059 & 25.307 & 5,24 & 1.830 .935 & 70,97 \\
\hline
\end{tabular}

Fuente: Instituto Nacional de Estadística e Informática. INEI.

Hill (2011) considera que en las últimas tres décadas han ocurrido cambios fundamentales en las economías nacionales pues se ha pasado de un periodo en el que se buscaba la autonomía a través de barreras al comercio internacional y a la inversión extranjera, a un proceso en el cual se busca promover el comercio y la inversión, sumando a este proceso, se destacan también los avances en las tecnologías de la información y en los medios de transporte. Los países, en esta nueva etapa, buscan modificar su cartera de productos exportados. Añaden productos que antes no hacían parte de su portafolio y que ahora producen teniendo conocimiento de que tienen ventajas comparativas frente a otros países y que deben aprovecharlas a través de la diversificación. Los cambios que están ocurriendo generan oportunidades que 
los países deben aprovechar. Las mismas ideas en cuanto a las oportunidades que se presentan a los países con orientación a las exportaciones las expresan Czinkota et al. (2007) y Daniels, Radebaugh, y Sullivan (2013).

Como todos los países buscan obtener provecho, la competencia entre ellos y sus empresas se hace intensa. Lo mismo ocurre dentro de cada país, la competencia se intensifica entre los emprendedores orientados a la internacionalización. Es por eso que los actores apelan a dos recursos importantes de los negocios: la productividad y la diferenciación del producto, expresada a través de la calidad del proceso, la que tiene que coincidir con la calidad percibida por el consumidor. La competencia es útil porque ayuda a que los dos factores mencionados se consideren relevantes entre los tomadores de decisiones políticas y empresariales. De ahí que Porter (2012, p. 359) exprese que los países y sus empresas consideren que "es necesaria una estrategia mundial, no nacional".

En Perú, una actividad que tiene un crecimiento alentador es la agricultura, tal como se expuso en la tabla 1. Aunque el aporte de la agricultura a la conformación del PBI ha disminuido, no implica que el número de hectáreas sembradas y cosechadas disminuya. El crecimiento está influenciado por el incremento significativo de las exportaciones agrícolas que se han multiplicado por 11 en el período 2010-2015. El impulso de este crecimiento se inicia en el año 2008. A fines del 2015 los principales productos exportados son los que se muestran en la tabla 2 y representan el 54,5 $\%$ del total de las exportaciones agrarias, destacando el café que es un producto agrícola tradicional y los productos agrícolas no tradicionales tales como uvas frescas, espárragos frescos y aguacates (paltas). El Ministerio de Agricultura y Riego (Minagri, 2016, p. 10) lo expresa de la manera siguiente y se corrobora con lo expuesto en la tabla 2:

Luego de casi 30 años con una balanza comercial deficitaria de productos agropecuarios, a partir de la última década se empezó a cerrar esta brecha por el fuerte incremento de las agro-exportaciones (que representan, al 2014, el $12.8 \%$ del total de las exportaciones del país). Esta expansión exportadora se ha concentrado en productos como café (tradicional), espárragos frescos y en conservas, así como uvas, mangos, cacao, palta y la quinua (no tradicionales).

El proceso de rápido crecimiento de las exportaciones agrícolas es resultado de la promoción de los productores a gran escala que cuentan con capital, tecnología y experiencia en producción y mercados. El papel de los pequeños agricultores es limitado en este camino de éxito, en el cual hay factores propios de ellos y también externos, lo que no implica que no sean considerados en la economía de un país como una actividad estratégica. Al respecto, la sociedad tiene que reconocer el papel 
de los pequeños agricultores en cuanto a la seguridad alimentaria, la reducción de la pobreza y el desarrollo sostenible.

Tabla 2. Las diez exportaciones agrarias por principales subpartidas arancelarias

\begin{tabular}{llll}
\hline \multirow{2}{*}{.$^{\circ}$} & Producto exportado (subpartida arancelaria) & $\begin{array}{l}\text { Valor FOB } \\
\text { (miles de USD) }\end{array}$ & Porcentaje \\
\hline 1 & Café sin tostar, sin descafeinar & 576.562 & 10,91 \\
\hline 2 & Uvas frescas & 690.379 & 13,06 \\
\hline 3 & Espárragos frescos o refrigerados & 416.225 & 7,88 \\
\hline 4 & Aguacates (paltas), frescos o secos & 303.779 & 5,75 \\
\hline 5 & $\begin{array}{l}\text { Arándanos rojos, mirtilos y demás frutos del género } \\
\text { vaccinium frescos }\end{array}$ & 95.804 & 1,81 \\
\hline 6 & Mangos y mangostanes, frescos o secos & 194.169 & 3,67 \\
\hline 7 & Cacao en grano, entero o partido, crudo & 183.092 & 3,46 \\
\hline 9 & $\begin{array}{l}\text { Bananas incluidos los plátanos tipo cavendish } \\
\text { valery frescos }\end{array}$ & 145.096 & 2,75 \\
\hline 10 & Espárragos preparados o conservados, sin congelar & 131.065 & 2,48 \\
\hline Total de las diez principales exportaciones agrarias & 2.879 .505 & 2,71 \\
\hline Total de exportaciones agrarias 2015 & 5.285 .000 & 100,0 \\
\hline
\end{tabular}

Fuente: Minagri (2017).

Sin embargo, dentro de sus limitaciones menciona como una de las principales dificultades el acceso al crédito, el cual posibilita el ingreso a una ruta de éxito. Es en este proceso contradictorio que se debe impulsar el contexto de la producción agrícola. Ser parte de un proceso de globalización de la economía y de una creciente urbanización implica la reestructuración del proceso de producción en el que la diversificación es parte importante de la respuesta y se evidencia por la producción del sector agricultura de Perú, aunque hay actividades agrarias que todavía no tienen un papel importante en las exportaciones.

En el contexto de una economía agraria articulada a la internacionalización se encuentran los pequeños agricultores cuyo nivel de atomización origina una baja capacidad de negociación de su oferta (Minagri, 2016). Con tal consideración, el Ministerio se fija como un objetivo específico el de "incrementar la competitividad agraria y la inserción a los mercados, con énfasis en el pequeño productor agrario" (Minagri, 2016, p. 8). La inserción implica la asimilación a asociaciones de productores, en un inicio, para luego integrarse a cadenas de exportación. La evidencia, aunque es poca, explica 
que luego hay algunos pequeños productores que se separan por haber superado las expectativas de sus socios, en cuanto a su producción y generación de valor.

La investigación en los pequeños agricultores de Lunahuaná indica que el 100,0 \% de ellos (anexo 1) considera que es importante que su producción se exporte, y esto puede ocurrir a través de la formación de asociaciones (anexo 2), situación con la cual el 92,3 \% de los entrevistados está de acuerdo, esto podría ocurrir a través de una organización que tiene experiencia en los negocios internacional (anexo 1) motivo por el cual se adecuaría a los estándares tal como lo manifiesta el 86,1 \% (anexo 1) de los entrevistados.

Pérez (2017) considera conveniente la integración de este grupo a la cadena de exportaciones, pero cuidando el nivel de dependencia de sus ingresos, además debe fortalecer su canal de distribución interna. Sin embargo, lo mejor es que ellos tengan la propia gestión de sus negocios, pues de esa manera están más cerca al conocimiento de las innovaciones y a los cambios en el mercado. Aranguri (2017) añade que tal integración les ayuda generar productos de mayor calidad y un valor diferencial a su producción, "además de mejorar la oferta exportable y hacerlos más competitivos". Lo último, puede generar lo expresado en el párrafo anterior en cuanto a la disociación, lo que ocurre por el fortalecimiento de la gestión (mejora de la producción, conocimiento del mercado) como unidad familiar que está en capacidad de participar en el mercado interno y producir "alimentos para nichos de mercados externos" tal como afirma Ocaña (2017, p. 1).

Maletta (2017) expone que la inmensa mayoría de pequeños agricultores en Perú pertenece a la categoría de agricultura familiar, que incluye a unidades productivas tradicionales de subsistencia y unidades modernas y capitalizadas. La Asamblea General de la Organización de las Naciones Unidas en la Resolución A/RES//66/222 -Año Internacional de la Agricultura Familiar- (2012, p. 1) afirma que:

La agricultura familiar y las pequeñas explotaciones agrícolas son una base importante para la producción sostenible de alimentos orientada a lograr la seguridad alimentaria. Asimismo, reconoce la importante contribución que la agricultura familiar y las pequeñas explotaciones agrícolas pueden suponer para el logro de la seguridad alimentaria y la erradicación de la pobreza.

La Resolución de la ONU es reconocida por el Ministerio de Agricultura y Riego (2015) y por tanto es un elemento importante para determinar la política sectorial. De otra parte, el Ministerio menciona que "la agricultura familiar es responsable de la provisión del $70 \%$ de los alimentos en el mundo y es la base de la producción sostenible de alimentos" (Minagri, 2015b, p. 15). El reconocimiento de que los pequeños agricultores hacen posible la seguridad alimentaria, o la capacidad de surtir de alimentos 
en los momentos requeridos a los consumidores locales, es la ventaja del pequeño agricultor que debe ser apoyada por el Estado y los empresarios. El Estado, otorgándoles las herramientas (gráfica 1) que mejoren su producción y productividad, y los empresarios, integrándolos al mercado internacional como parte de sus proveedores de productos exportables. Así puede hacerse posible convertirla en una ventaja competitiva sostenible que permita estar en condiciones de mejorar la calidad de vida del pequeño agricultor. En la economía nacional, la pequeña agricultura tiene un papel estratégico y es conveniente que reciba el apoyo que le permita superar las barreras que el mismo mercado le presenta.

La pequeña agricultura tiene una diversidad de barreras que debe superar y el desafío es convertirlas en las herramientas que posibiliten el desarrollo de la actividad agraria. Dentro de esa diversidad se identifica a una de ellas y es la que sirve como combustible para mejorar su participación en el mercado internacional. La barrera que limita su actividad estratégica está relacionada con el financiamiento, como elemento parcial para el incremento de la productividad y la calidad de la producción, lo cual, ante un acceso fluido, permite superar los dos puntos expuestos acerca de la producción sostenible y la erradicación de la pobreza. La transformación del pequeño agricultor se relaciona con el financiamiento, concepto este que no solo implica desembolsos de dinero, sino que abarca todo un cambio estructural que asimilan los miembros de la cadena de valor.

La importancia de tal acción la expresan Daneshvar et al. (2017), quienes manifiestan que existe evidencia de que la inclusión financiera de los pequeños agricultores tiene efectos positivos en sus hogares, así como en el aspecto macroeconómico. Por tanto, la inclusión es una herramienta con la suficiente capacidad para modificar favorablemente la economía del pequeño agricultor. Teniendo la posibilidad del financiamiento pueden integrarse en mejores condiciones a la cadena de valor de un exportador importante, aunque, como se menciona, la obtención de crédito es solo una de las herramientas con que debe contar el pequeño agricultor. Los citados investigadores, respecto al financiamiento, consideran que (2017, p. 19):

La inclusión financiera consiste en la promoción de un acceso asequible, oportuno y adecuado a una gama de productos y servicios financieros regulados, así como la expansión de su uso por parte de todos los segmentos de la sociedad a través de la implementación de acciones personalizadas e innovadoras que incluyan educación y conocimientos financieros con el fin de promover el bienestar, y la inclusión económica y social.

Oddone y Padila (2017, p. 16) explican que "una cadena de valor comprende la amplia variedad de actividades requeridas para que un producto o servicio transite por diferentes etapas, desde su concepción hasta su entrega a los consumidores y la disposición final después de su uso". 
Gráfica 1. Herramientas que mejoran la capacidad de producción del pequeño agricultor

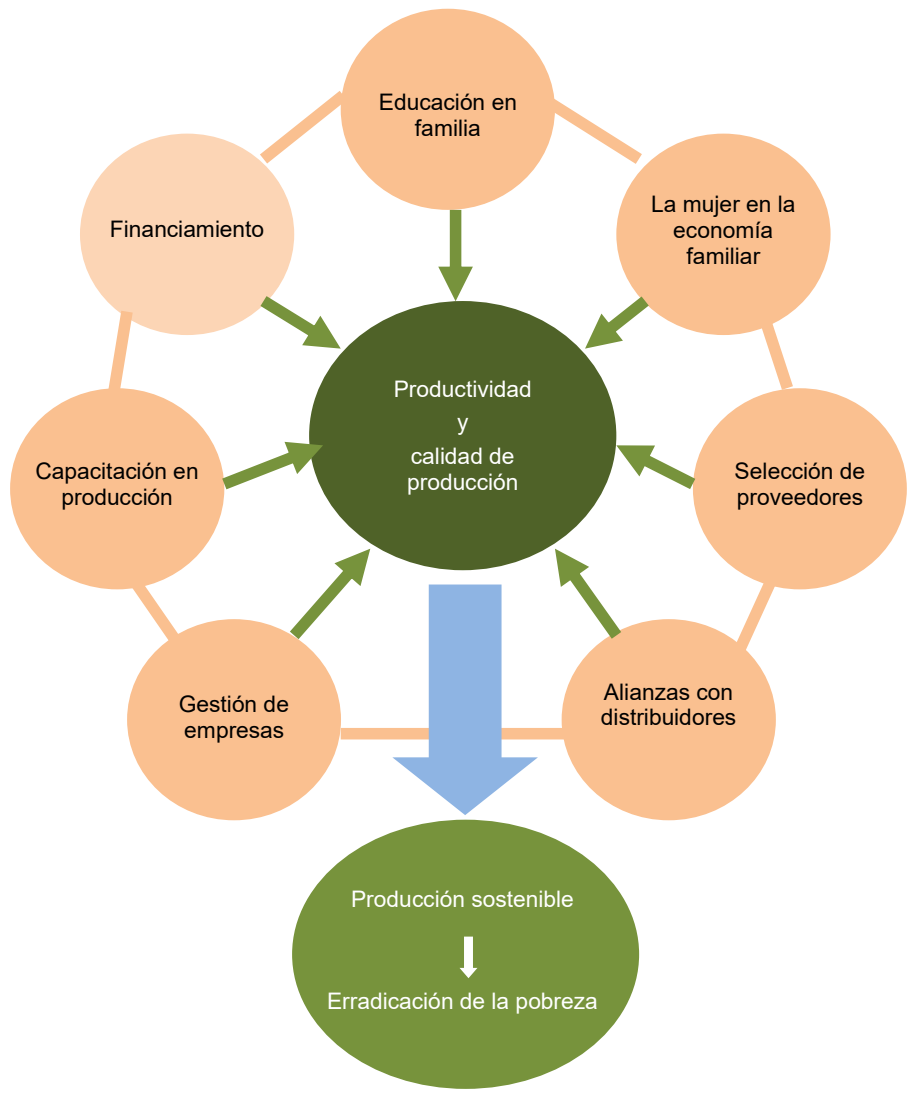

Fuente: elaboración propia

Cada integrante de la cadena se denomina eslabón y cada uno cumple una labor determinada que beneficia al productor en su relación con el consumidor final, aunque no trate directamente con él, motivo por el cual debe evaluarse a cada uno toda vez que de este proceso depende si el eslabón otorga valor a la producción. Uno de esos eslabones es la institución financiera.

Es importante la idea de que los pequeños agricultores se inserten en el mundo de las finanzas, tal como expone Cotler (2017), deben el Estado y las instituciones dedicadas a este negocio preocuparse por la creación y oferta de instrumentos de fácil entendimiento y aplicación, de modo que se ajusten a las posibilidades de los demandantes. Que una institución financiera reconocida por el Estado lo realice implica que se trata de una transacción formal, en donde existen documentos de derechos y deberes de cada una de las partes que intervienen. El demandante ingresa 
al mundo de la formalización, que puede ser total o parcial que es cuando continúa solicitando los servicios financieros de personas no registradas en las instituciones supervisoras de la actividad crediticia.

Explicaciones similares en cuanto a la instrumentalización, tal como expone Cotler (2017), también las expone Pérez y Titelman (2018) y León (2018), en donde a través del sistema financiero la creación de productos financieros adecuados ayuda a la formalización de las pequeñas empresas, clasificación que incluye a los pequeños agricultores. León (2018, p. 192) expresa lo complejo de este proceso que puede estar ocurriendo en otros países latinoamericanos y que puede considerarse una limitación para incluirlos o bancarizarlos: "es difícil conocer el total de empresas que existen en el Perú, dado que algunas no están registradas".

La integración del pequeño agricultor es un proceso que abarca diversas actividades, y es el factor financiero el que puede apoyar mejor para sostener su inversión en la nueva agricultura o agricultura de exportación. Para las instituciones financieras implica adaptarse a las características de los nuevos asimilados por lo que debe diseñar nuevos tipos de canales de distribución. El Estado debe analizar la posibilidad de subsidiar indirectamente estos créditos, la creación de algún mecanismo que implique un bajo costo financiero y analizar los costos adicionales que asume el proveedor o institución financiera.

El proceso de integración es complejo, o como manifiesta Casas (2017, p. 4) "ese es el gran dolor de cabeza" del proceso de formar cadenas con los pequeños agricultores. Su experiencia es el haber participado en procesos de integración promovidos por el Estado y los inversionistas privados y, en su opinión, la idiosincrasia del pequeño agricultor no está a la altura de la exigencia que implica este cambio. En su opinión (p. 4) "tiene que haber un cambio generacional" es decir que los hijos asuman la dirección de producción, aunque también se hace complicado porque los hijos se marchan ya que no les es grato enfrentarse con sus padres. Aunque lo expuesto por Casas (2017) no se puede generalizar, está implicando la existencia de barreras de los mismos agricultores para integrarse en mejores condiciones con los exportadores. Salas (2015, p. 6) menciona que "Los problemas que se presentan dentro de las estructuras sociales como las asociaciones se relacionan con los problemas de acción colectiva como una mala gestión, engaños y aprovechamiento se los directivos y miembros de la asociación".

Los pequeños productores de Lunahuaná expresan una voluntad favorable a la asociación con los exportadores experimentados cuando dicen (anexo 1) que están dispuestos a sujetarse a los estándares (34,6 \%), que los capaciten en tecnología (49,2 \%), están dispuesto a firmar cartas de compromiso (41,5\%), se convierten en 
un agente promotor de la exportación en el valle $(41,5 \%)$ y como consecuencia deciden aumentar la producción (30,8 \%). El 30,8 \% (anexo 1) asume un compromiso total. Para ellos el Estado tiene un papel importante, además de los exportadores, ya que el 69,2 \% (anexo 1) de los entrevistados considera que una acción necesaria es la capacitación para mejorar la producción. También manifiesta, el 43,1 \%, que debe apoyarlos con el financiamiento de la campaña.

\section{SITUACIÓN ACTUAL DE LA PEQUEÑA AGRICULTURA Y LOS GRANDES EXPORTADORES}

Son múltiples los factores que afectan la vida económica de los pequeños agricultores los más conocidos, además de sus características internas, son los efectos del cambio climático, el acceso a semillas y abonos que incrementen la productividad, el aumento de la degradación de los suelos, las disputas por el recurso hídrico, deficiente infraestructura para interrelacionarse con otras comunidades, falta de planificación que origina sobreproducción y disminución de precios de sus productos, la migración de los jóvenes a la ciudad. Aun así, no significa que pierda importancia en la economía peruana, sino que es lo contrario, lo que origina que se convierta en un punto crítico de abastecimiento, en especial para las zonas urbanas.

Ante tal panorama, se mantiene que la articulación o involucramiento del pequeño agricultor a la cadena de exportación es un desafío que tiene el Estado, que requiere el diseño de actividades debidamente planificadas e interrelacionadas con los otros sectores, que incluya mantener determinadas actividades productivas y mejorarlas en su sistema de producción. La acción debe implicar asumir la diversificación productiva, la que debe estar relacionada al comercio internacional. La consecuencia del proceso debe llevar a un cambio estructural aprovechando la capacidad productiva de los pequeños agricultores. El cambio es una actividad que para el Ministerio de Agricultura y Riego implica:

Procesos y estrategias que permiten acercar a los pequeños productores agrarios en forma más directa y estable a los mercados, a través de alguna modalidad de compromisos con agroindustrias, exportadoras u otros agentes privados en el mercado, identificando y proponiendo las medidas que podrían contribuir a una articulación mejor en beneficio de los pequeños productores agrario (Minagri, 2015b, p. 37).

En el Informe de la Secretaría Técnica de la Conferencia de las Naciones Unidas sobre Comercio y Desarrollo (Unctad, 2015) se expone que los pequeños agricultores son descuidados por la política en contrapartida por la preferencia a los agricultores de grandes extensiones, que normalmente producen para exportar. Se ha producido un crecimiento significativo en la compra de tierras agrícolas por parte de inversionistas 
con el propósito de los negocios internacionales. El Unctad (2015, p. 20) expresa que "las inversiones del sector privado se han visto determinadas fundamentalmente por la perspectiva de un alza en los precios de los productos agrícolas básicos y una mayor rentabilidad del capital invertido, mientras que las inversiones públicas han obedecido a motivos de seguridad alimentaria y energética".

Para Unctad (2015) también los pequeños agricultores son elemento clave para alcanzar los objetivos de seguridad alimentaria. Les falta integrarse al comercio internacional o ser asimilados a esta actividad. Son pocos los agricultores que lo hacen y su producción exportadora se relaciona con productos agrícolas tradicionales (commodities) como el café y, más recientemente, el cacao, aprovechando la oportunidad que se presenta por la demanda internacional de estos productos. La integración a una cadena de exportación debe ser bien recibida considerando que a los pequeños agricultores les permite su sostenibilidad familiar y también cuidar lo frágil que es la seguridad alimentaria.

La acción inicial es acerca de quién invierte en potenciar al pequeño agricultor y la respuesta está por el papel estratégico del Estado, poniendo énfasis en las siete actividades que se exponen en la gráfica 1. En Perú, el organismo ejecutor de tal actividad es el Ministerio de Agricultura y Riego como la institución que diseña el marco normativo en una estrategia que interrelaciona a varias instituciones públicas. Además, realiza las actividades necesarias para agregar valor a la producción del pequeño agricultor, lo que permite integrarlos a la cadena de los exportadores, de la cual pueden ser parte, para luego independizarse y exportar directamente al comprador internacional. Porque pueden ser parte de los proveedores de mercados especializados o nicho.

Ocaña (2017) opina que es conveniente que los grandes exportadores integren a los pequeños agricultores a su cadena de exportación, apoyándolos en el manejo técnico para la obtención de una producción de calidad de modo que se esté en capacidad de exportar. Magallanes (2017) añade que también debe haber un acuerdo de precios entre el exportador y el pequeño agricultor, así como compromisos de mejora en la organización (del pequeño agricultor), capacitación, desarrollo de sistemas de contratos y conocimiento de cómo apalancarse financieramente. Es alentadora la opinión de Pérez (2017, p. 2) "ambos pueden beneficiarse del mismo mercado. Si ambos crecen, ambos podrán ganar y fortalecerse mutuamente".

En la investigación realizada con los pequeños agricultores de Lunahuaná ellos expresaron (anexo 2) que los compromisos más importantes que debe asumir el exportador es que a sus productos se les otorguen precios justos $(73,1 \%$ y que 
les brinden apoyo para aprender nueva tecnología (65,4\%). El financiamiento también lo consideran importante y se ubica en el tercer lugar (42,3\%). El proceso implica para los pequeños agricultores la posibilidad de cambiar cultivo (anexo 2) ante lo cual opinan que lo aceptarán, pero es necesario un ingreso $(43,1 \%)$, lo que puede ser una limitante para la integración.

La sociedad y el fortalecimiento de la relación entre los pequeños agricultores y los exportadores es un proceso complicado. Por ejemplo, en el párrafo anterior se expresa que el agricultor está dispuesto al cambio, pero le preocupa cómo asume su situación de momento tomando en cuenta que sus tierras son los que generan su sustento familiar. Unctad (2015) cita cuatro factores globales que determinan barreras para que se produzca la asociación, sin que esto signifique no pueden ser superadas, pero que hacen conocer que es un camino con dificultades:

- La intensificación de la competencia entre los países que origina que los exportadores busquen integrar cadenas de valor que no afecten sus costos, haciendo así complicada la integración del pequeño agricultor al mercado internacional.

- El incremento de los productores exportadores en cada país, en especial en los emergentes, quienes han sumado a sus procesos la mecanización de la producción lo cual también hace complicado la asimilación a las cadenas.

- Comienza a sentirse el efecto de las migraciones, en cuanto a la disminución de la mano de obra, que se está asimilando a los grandes productores agrarios o a la producción urbana.

- El incremento de la inversión, nacional y extranjera, que adquiere grandes extensiones territoriales fijándose en el rendimiento de sus costos (aumento de la productividad) marginando de esta manera al pequeño agricultor.

Los cuatro puntos citados expresan el contexto que debe considerarse en el proceso de integración del pequeño agricultor a la cadena de valor de las exportaciones. Son restricciones que afectan la posibilidad de ser considerados en el proceso de asimilación a los mercados internacionales. Debe tenerse presente que en la relación exportador-pequeño agricultor ambos calculan los beneficios y los costos de tal sociedad antes de lograr un acuerdo común, aunque puede haber asimetría en la información motivo por el cual el pequeño agricultor debe asumir un mayor riesgo. Para disminuir el riesgo, por parte del gran inversionista, se tiene que "asociar a los productores" tal como opina Díez (2017, p.3).

Un aspecto a considerar en el desarrollo del pequeño agricultor es la formación de asociaciones de productores de modo que consoliden una cadena de valor lo 
suficientemente sólida y sostenible. Las experiencias en el Perú de desarrollos favorables relacionados a la asociatividad no son ejemplares, así que su mismo comportamiento ha generado desconfianza entre los agricultores. La asociatividad es importante porque permite generar volumen de producción que establece un mejor manejo de negociación con los compradores intermediarios, muy en especial en el establecimiento de los precios a través de la economía de escala, tal como expresa Salas (2016, p. 2):

Las asociaciones de productores agrarios ofrecen un espacio de interacción para la construcción de relaciones y redes sociales, las cuales favorecen el flujo de información entre sus miembros; quienes pueden usar dicha información para colocar sus productos en mercados nuevos y distantes. Además, las asociaciones permiten superar el problema del minifundio, ya que las transacciones comerciales se manejan de forma colectiva y directa con los compradores, lo cual otorga cierto poder de negociación a los productores y también reduce la incertidumbre en los precios de venta

Pérez (2017) menciona la relación entre la asociatividad y la posición del pequeño agricultor y añade que "sería garantizar su posición con una asociación que la respalde y que le permita mejorar su negociación con una mayor oferta y finalmente, garantizar que haya capital humano local (familiar) para los reemplazos de gestión como plan de contingencia". En su opinión, Ministerio de Agricultura y Riego no cuenta con los suficientes recursos para llevar a cabo las tareas que son necesarias. Asimismo, considera que la autoridad agraria debe buscar la integración con otros sectores públicos para que sirvan de apoyo en esta estrategia. El Estado, a través de sus instituciones, debe considerar que el proceso es una oportunidad que le permite actuar de manera eficiente en la asignación de los recursos públicos.

La asociación de productores se convierte en un eslabón de la cadena del producto, a través del cual los proveedores y sus compradores son parte de la cadena de comercio internacional. La formación de la cadena de valor, es un proceso de largo aliento en donde el proceso de selección implica la disminución de todos los costos que asume la asociatividad. La asociación debe considerar que todos los miembros deben estar dispuestos a dar los recursos para fortalecer la cadena. Puede ser el caso de información acerca del mercado y sus tendencias, las nuevas tecnologías para producir y distribuir mejor, los sistemas de transportes adecuados, oportunidades de nuevos mercados y nuevos productos, incluso acerca del costo de financiamiento. Consolidar una cadena de valor sostenible es una acción compleja pues implica fortalecer y asegurarse que así sea en cuanto a fortalecer relaciones de comportamiento al interior de la misma asociación como fuera de ella. La cantidad de relaciones que tienen que considerarse se representan en la gráfica 2. 
Gráfica 2. Cadena de valor de un producto agrícola de productores asociados

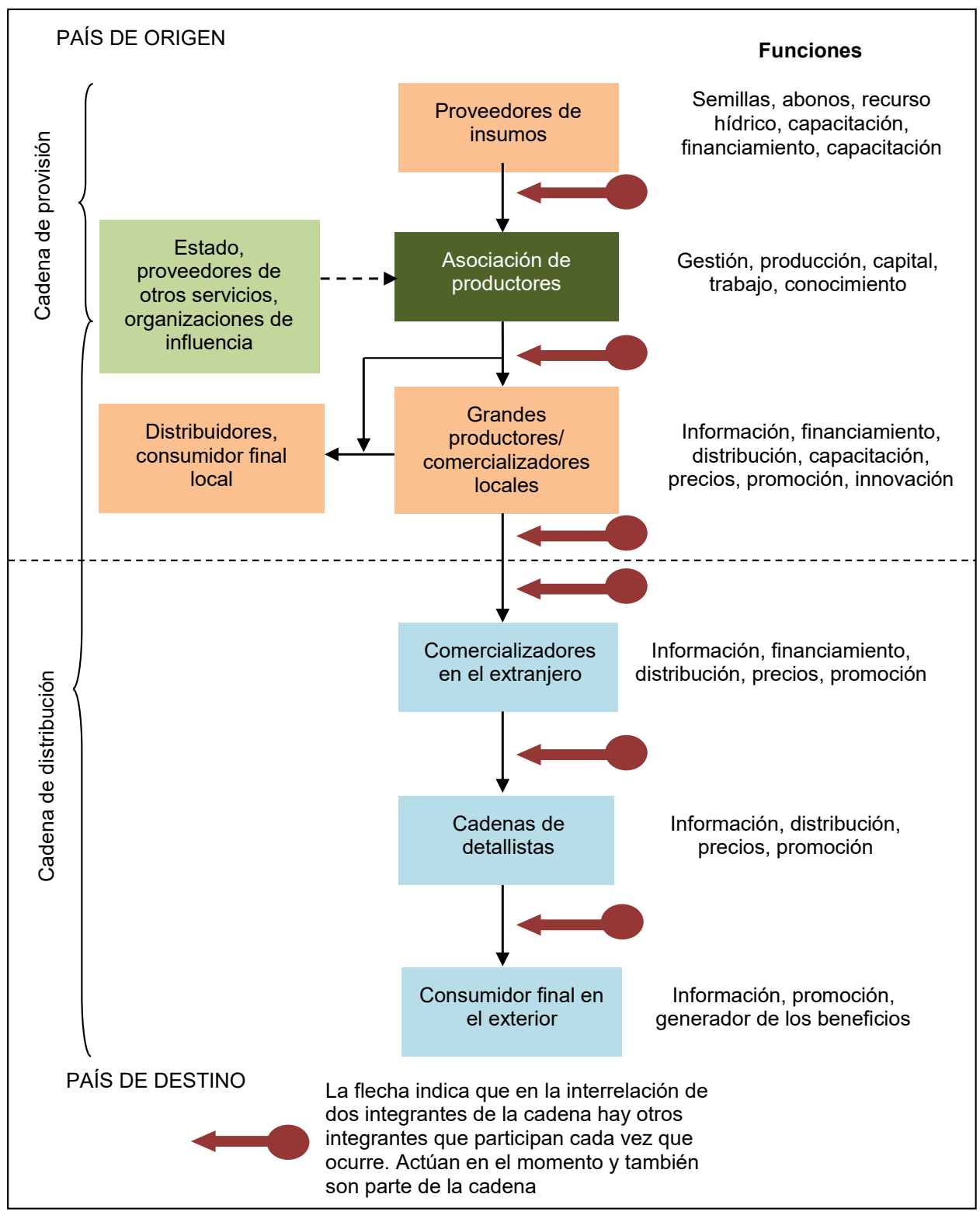

Fuente: elaboración propia

Porter (2012) expresa la preocupación de la dimensión de la cadena de valor en cuanto dónde se inicia y dónde concluye. La cadena de valor de una empresa, cualquiera sea el sector en que actúe, es parte de una cadena mayor a la cual denomina 
(p. 112) "sistema de producción de valor", que incluye también a los proveedores, tal como se expone en la gráfica2. Es decir, debe incluirse en tal cadena a los proveedores, motivo por el cual la relación de interdependencia que se origina es asegurar la fortaleza de la interrelación entre la cadena de provisión y la cadena de distribución. En el caso del pequeño productor agrícola, por tanto, debe comenzar por asegurarse lo que da origen a su producción o sea el proceso de selección de semillas. Buenas semillas darán buenos frutos. Reconocer la dimensión de la cadena de valor significa entonces el esfuerzo de disminuir los costos a través de la colaboración.

Oddone y Padilla (2017) consideran que la última década se manifiesta un creciente interés por establecer nuevas condiciones entre el Estado, el mercado y la sociedad, con la intención de que los gobiernos tengan un papel más dinámico en el desarrollo de la sociedad. En este nuevo ambiente es que las cadenas de valor deben servir para fortalecer esta nueva ecuación, en torno a productores, productos y territorios específicos. La participación del sector público en concordancia con los agentes influenciadores debe permitir acuerdos que permita la integración o el fortalecimiento de las cadenas de valor, lo cual incluye a los pequeños agricultores como grupo estratégico.

Por la perspectiva que hay en el mercado internacional, en relación a los productos agrarios, el Estado y sus instituciones deben ver el apoyo eficaz al pequeño agricultor como la posibilidad de brindar un mayor bienestar a las familias que las componen y también como una fuente de incremento de beneficios económicos y sociales. Las políticas, estrategias y acciones que para tal fin se establezcan pueden considerar que la competencia internacional se ha intensificado, pues es una preocupación de varios países emergentes aprovechar esta oportunidad que ofrece el mercado internacional para otorgar un mejor bienestar a los productores del campo. El apoyo debe considerarse como una inversión que posibilita un rendimiento aceptable, los beneficios mayores que los costos.

El mismo Estado tiene que establecer sus propias economías de escala a través de la promoción de la asociatividad, lo que implica que a mayor cantidad de productores involucrados sus costos disminuyen. Esto es necesario porque permite que se produzca la integración del pequeño agricultor a la cadena de exportaciones de manera que el productor esté en mejor capacidad de establecer sus márgenes de ganancia, así como sus decisiones de producción en cuanto de diversificar o no. Las nuevas condiciones globales deben ser consideradas como un impulso para los pequeños agricultores toda vez que permiten visualizar nuevas necesidades que pueden ser satisfechas, en donde la actuación del Estado a través de sus políticas tiene una orientación al mercado internacional. 
Quiroz (2017, p. 44) expresa la importancia de incluir en la cadena a los distribuidores considerando que "los productores y las empresas de menor tamaño en la subregión enfrentan más dificultades para colocar sus productos y servicios en mercados locales e internacionales". Para estar en mejor capacidad de negociación con los comercializadores los países deben transitar de productos agrícolas tradicionales, a productos no tradicionales, motivo por el cual se debe diversificar, lo que implica promover productos nuevos y tengan demanda en el mercado internacional. Caso contrario el eslabón comercializador se convierte en una debilidad. Quiroz también menciona que "el papel de los intermediarios es complejo: por una parte, cubren necesidades productivas para la movilización de los productos $y$, por otra, capturan un importante margen de ganancias en detrimento de las ganancias de los pequeños productores"

Los pequeños agricultores deben tener en consideración estas características al diseñar sus estrategias de integración, que es parte de un proceso inicial. El comercializador tiene ventaja de información sobre el pequeño productor, pues está en un proceso continuo de analizar la sensibilidad de la demanda. Quiroz (2017) manifiesta que el Estado debe reconocer el potencial de las actividades agrarias de los pequeños productores para que, de esta manera, contribuya al cambio que ahí se requiere y que para tal caso debe asignar el presupuesto correspondiente.

Si bien es estratégica la posición del pequeño agricultor, también es frágil, lo cual puede afectar a la economía nacional, en la relación con la demanda internacional, los precios de los productos agrícolas alimenticios y en especial con la comercialización, debido a que la parte débil de los pequeños productores. Los precios agrícolas son volátiles y esto debe ser considerado al planificar la actividad. Es una parte del análisis que considera el Ministerio de Agricultura y Riego (2015, p. 33) y que es considerada al establecer las políticas y programas correspondientes:

También hay argumentos convincentes que sugieren que, además de ser más elevados, los precios de los productos alimenticios básicos serán más volátiles en el futuro. Si aumenta la frecuencia de los fenómenos meteorológicos extremos, las crisis de la producción serán más frecuentes, lo cual contribuirá a que los precios sean más volátiles.

Las perspectivas de los productos agrícolas en el mercado internacional son favorables y los resultados que se pueden obtener deben ser compartidos por los agentes económicos. Se originan nuevos tipos de demanda que generan oportunidades a países como Perú que tiene una diversidad agrícola y con tierras con capacidad de adaptación a los nuevos requerimientos. Acemoglu y Robinson (2012, p. 347) opinan que "las instituciones políticas y económicas inclusivas tienden a crear un círculo virtuoso, un proceso de retroalimentación positiva, lo que aumenta la probabilidad de que estas instituciones persistan e incluso se expandan". 


\section{LA PEQUEÑA AGRICULTURA Y EL PAPEL DEL ESTADO}

Acemoglu y Robinson (2012) plantean que, para que un país no fracase, debe dejar de ser un país con larga historia extractivista, la misma que no genera los suficientes estímulos para que la gente ahorre, invierta e innove. Ante tal circunstancia, los países deben transitar a una transformación inclusiva, considerando que este proceso no es fácil de llevar a cabo y tampoco presenta resultados inmediatos. Tanto el Estado como los sectores empresariales deben ser los agentes dinámicos de este cambio. El rompimiento del molde implica crear incentivos para que se genere una economía inclusiva, en donde a la agricultura le corresponde un papel importante.

En el tránsito hacia una sociedad más inclusiva ocurre el esfuerzo de los gobernantes de los países con tales características económicas y sociales, en cuanto a la inclusión y diversificación de su economía, lo que genera que haya una mayor oferta de productos de nuevos países proveedores. La globalización permite que exista la posibilidad de abastecer esos mercados en los cuales la demanda se vuelve más exigente y la competencia se intensifica, por tanto, los países productores deben diseñar estrategias que les permita obtener ventajas. En este ambiente, es válida la expresión de Porter (2012) cuando expone sobre la importancia de la evolución de la competencia, que se convierte en un elemento desestabilizador, siendo este factor lo que permite la prosperidad de los países. La intensidad de la competencia se dará en todos los sectores en los cuales un país considera que tiene una ventaja.

Es en este panorama que Arteaga (2016) manifiesta que ocurre una tendencia del sector agrícola peruano a tener un menor valor relativo en la formación del PIB, lo que también puede apreciarse en la tabla 1. Esto ocurre a pesar de que el número de hectáreas sembradas ha aumentado, el trabajo intenso del Minagri apoyando a los pequeños agricultores, los gobiernos regionales y locales, y las actividades de otros organismos públicos y privados. Este comportamiento debe llevar a la expansión del sector, sin embargo, la realidad es otra. La reducción del producto agrario afecta a aquellos que tienen una menor posibilidad de adaptarse a la agroindustria, al mercado internacional. Para mejorar tal tendencia es conveniente considerar que Perú no tiene un solo tipo de sistema en la agricultura, sino que esta abarca hasta cuatro tipos (tabla 3) y por lo tanto la propuesta estratégica debe elaborarse en función a estas diferencias, lo que puede generar mejores resultados.

Desde un punto de vista de la competencia intensa, la propuesta estratégica puede considerar cómo se distribuirán los recursos escasos para dar una respuesta a la manera de enfrentar la competencia global dentro de un proceso sostenido o de largo plazo. El Estado decide a que sector se le otorga un mayor esfuerzo. En la elaboración de las macroestrategias para el sector agrario, el Ministerio de 
Agricultura y Riego (2015b) establece seis objetivos de prioridad A para el período 2015-2021, los que se relacionan cadenas de valor (estrategia 1), calidad de producto (estrategias 2 y 5), producción y productividad (estrategias 3 y 4) e información de la oferta (estrategia 6). Las estrategias se detallan a continuación y se complementan con otras de prioridad B y C tal como puede apreciarse en la gráfica 3.

- Mejorar la articulación de la pequeña agricultura a los mercados.

- Fortalecer el mejoramiento genético de las especies con demanda potencial en los mercados.

- Mejorar la generación, disponibilidad, acceso y adopción de tecnologías agrarias.

- Mejorar la infraestructura productiva agraria y de riego.

- Fortalecer el sistema de sanidad agraria e inocuidad agroalimentaria.

- Desarrollar un sistema integrado de información sectorial agraria.

Tabla 3. Tipo de agricultura y características predominantes

Tipo de agricultura

Características predominantes
Importancia con

respecto al PIB

del sector agrícola

\begin{tabular}{|c|c|c|}
\hline $\begin{array}{l}\text { Unidades empre- } \\
\text { sariales consoli } \\
\text { dadas }\end{array}$ & $\begin{array}{l}\text { Producción intensiva con tecnología moderna. Inserción en } \\
\text { cadenas de valor. Plenamente articuladas al mercado externo } \\
\text { e interno, dinámico. Certificaciones logradas para varios } \\
\text { tipos de mercado. Alto nivel de gestión institucional. Gran } \\
\text { facilidad para financiamiento de la banca de multiservicios } \\
\text { Rentabilidad significativa. Sostenibilidad del negocio. }\end{array}$ & $\begin{array}{l}10 \% \text { PIB } \\
140.000 \text { ha } \\
(5,5 \%)\end{array}$ \\
\hline $\begin{array}{l}\text { Unidades empre- } \\
\text { sariales parcial- } \\
\text { mente desarro- } \\
\text { lladas }\end{array}$ & $\begin{array}{l}\text { Producción intensiva con tecnología moderna. Inserción en } \\
\text { cadenas de valor. Plenamente articuladas al mercado externo } \\
\text { e interno, dinámico. Certificaciones logradas para varios } \\
\text { tipos de mercado. Alto nivel de gestión institucional. Gran } \\
\text { facilidad para financiamiento de la banca de multiservicios } \\
\text { Rentabilidad significativa. Sostenibilidad del negocio. }\end{array}$ & $\begin{array}{l}50 \% \text { PIB } \\
1.200 .000 \text { ha } \\
(47,2 \%)\end{array}$ \\
\hline $\begin{array}{l}\text { Unidades em- } \\
\text { presariales en } \\
\text { formación }\end{array}$ & $\begin{array}{l}\text { Producción a pequeña y mediana escala. Articulados a merca- } \\
\text { dos de consumo directo. Canalizan financiamiento de banca } \\
\text { de fomento. Gestión empresarial incipiente. Rentabilidad muy } \\
\text { impactada por el mercado. }\end{array}$ & $\begin{array}{l}36 \% \text { PIB } \\
800.000 \text { ha } \\
(31,5 \%)\end{array}$ \\
\hline $\begin{array}{l}\text { Unidades des- } \\
\text { articuladas del } \\
\text { mercado }\end{array}$ & $\begin{array}{l}\text { Producción muy fragmentada. Producción con baja tecno- } \\
\text { logía. Sin acceso a servicios del Estado. Dificultad para el } \\
\text { financiamiento. Orientadas al autoconsumo e intercambio. } \\
\text { Descapitalización continua. }\end{array}$ & $\begin{array}{l}4 \% \text { PIB } \\
400.000 \text { ha } \\
(15,7 \%)\end{array}$ \\
\hline
\end{tabular}

Fuente: basado en Arteaga (2016, p. 40). 
Gráfica 3. El pequeño agricultor en la estrategia del sector agrario

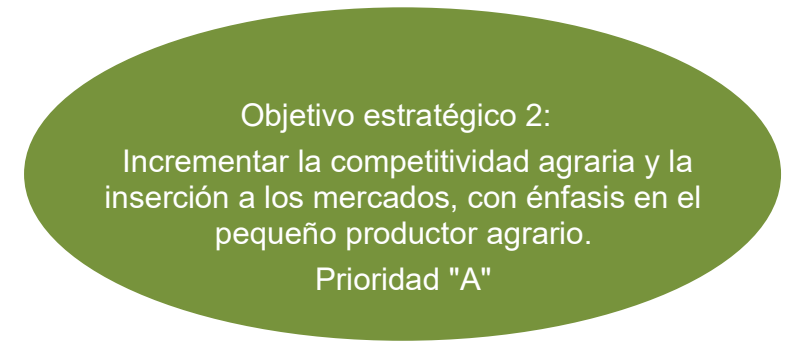

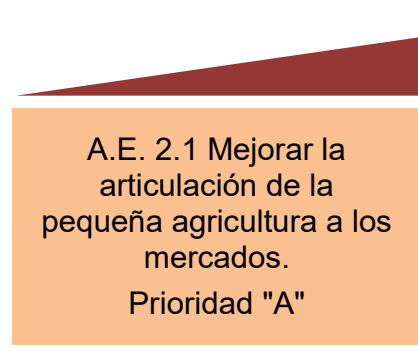

A.E. 2.4 Mejorar la infraestructura productiva agraria y de riego.

Prioridad "A"

A.E. 2.7 Propiciar el desarrollo de negocios agrarios sostenibles.

Prioridad "B"

A.E. 2.10 Facilitar el acceso del productor agrario a los servicios financieros.

Prioridad "B"

A.E. 2.12 Propiciar el desarrollo de negocios agrarios sostenibles.

Prioridad "C"
A.E. 2.2 Fortalecer el mejoramiento genético de las especies con demanda potencial en los mercados.

A.E. 2.5 Fortalecer el sistema de sanidad agraria e inocuidad agroalimentaria.

Prioridad "A"

A.E. 2.8 Promover el saneamiento físico legal y la formalización de la propiedad agraria.

Prioridad "B"

A.E. 2.11 Impulsar la conformación de organizaciones empresariales en los productores agropecuarios.
A.E. 2.3 Mejorar la generación, disponibilidad, acceso y adopción de tecnologías agrarias.

A.E. 2.6 Desarrollar un sistema integrado de información sectorial agraria. Prioridad "A"

\section{A.E. 2.9 Impulsar la reconversión y diversificación productiva de cultivos y crianzas con los productores agrarios.}

Fuente: Minagri (2015b).
A.E. 2.13 Fortalecer la articulación e institucionalidad agraria en los tres niveles de gobierno.


El papel del Estado en la economía nacional es un tema de continua discusión, en donde hay simpatizantes de qué tanto o qué tan poco participa para ayudar a la industria local a que actúe en la competencia internacional, estableciendo una serie de políticas que los ponga en similares condiciones o mejores que sus competidores. La idea central es que las empresas tengan la menor posible dependencia del Estado, sin que esto implique un nulo actuar. Como cita Porter (2012, p. 251) "los partidarios de una menor presencia oficial ignoran el papel legítimo que el Estado desempeña en la conformación del contexto y estructura institucional que rodea a las empresas y crear un entorno y situación que estimule a éstas a lograr ventajas competitivas". Asimismo, define el campo de acción (p. 251) cuando explica que:

El papel correcto del Estado es el de catalizador y estimulador. Es el de alentar -O incluso empujar-a las empresas a que eleven sus aspiraciones y pasen a niveles más altos de competitividad, aun cuando este proceso sea intrínsecamente desagradable y difícil. El Estado no puede crear sectores competitivos: solo pueden hacerlo las empresas.

Para la Cepal (2017) la producción y el comercio agrícola representan desafíos que obligan a los países latinoamericanos a trabajar en políticas que fortalezcan las potencialidades del sector agrícola, siendo tres los principales temas: i) incremento de la productividad, ii) reducción de la inequidad interna en las cadenas agroalimentarias y, iii) fortalecimiento de la resiliencia y la reducción del impacto ambiental de los sistemas productivos. La misma organización menciona que las perspectivas de crecimiento de la economía mundial son alentadoras lo que también debe mirarse con cautela por la aparición de políticas proteccionistas de los principales países compradores.

Cepal (2017, p. 53) manifiesta que "cuando se analizan los datos de comercio desde el punto de competitividad, entendida como la capacidad de sostener o expandir la participación de mercado de un producto o grupo de productos se pueden clasificar en cuatro grupos". Perú se ubica en la categoría I: países y regiones con VCE $>0$ y tasas de crecimiento positivas a diez años, que es la categoría que identifica a los países que muestran un mejor dinamismo de comercialización de productos agrarios frente a los productos internos que se llevan al mercado internacional y respecto al comportamiento de los competidores a nivel mundial.

La demanda de productos agrícolas será sostenible para los próximos años de manera que los países productores deben estar listos para tal oportunidad. Implica un aumento de la competencia entre los productores locales de cada país y entre los vendedores a nivel internacional. Cepal (2017) menciona que factores como la diversificación de productos para atender nichos de mercado, establecimiento 
de patrones para evitar la degradación ambiental y la presión sobre los recursos naturales, tener un sistema de información acerca de lo que ocurre y debe ocurrir en el país y en los compradores internacionales, conocimiento de tecnologías que incrementen la productividad y promoción de la investigación, son los factores que marcan la pauta de la competencia internacional. Sin embargo, también es conveniente lo que menciona Cepal (2017, p. 55) "aunque continuará existiendo un amplio grupo de consumidores sensibles a los precios, con el aumento en la población de clase media y en su poder de compra, se incrementará la demanda de productos premium, por lo que el consumidor priorizará cada vez más la calidad respecto del precio de los productos".

El seguimiento de las tendencias de consumo de los consumidores de los principales mercados internacionales marca la pauta a los productores que compiten por abastecer al mercado internacional de acuerdo a los cambios sociales. En este camino, deben considerarse los cambios que se están originando en el concepto de familia, tal como expone Cienfuegos (2014) considerando que en el siglo XX ocurren cambios demográficos significativos que empoderan a los consumidores individuales tales como la alfabetización, el tamaño de la familia, la ampliación de la cobertura médica y el crecimiento de la participación laboral femenina. Aunque, debe considerarse que si se consideran los diversos segmentos sociales ocurren asimetrías más relevantes en los grupos de menores ingresos.

Los productores deben estar alertas a los cambios que ocurren en el ambiente de los compradores finales. En el mercado, la oferta genérica de productos agrarios se divide en productos orgánicos y no orgánicos. También, se deben considerar los vegetales frente a otro tipo de alimentos como las carnes. El comprador, en su proceso de decisión, toma en cuenta una serie factores como el precio unitario, en tanto que los orgánicos tiene un precio unitario más alto, lugar de compra (cadena de supermercados), sustitutos y certificaciones entre otros; son estos factores los que guían la producción. Murcia (2016, p. 16) basado en una investigación que realizó Innova Market Insights' considera la potencialidad del mercado de los productores agrarios cuando manifiesta que "Cada vez hay más personas que, preocupadas por su bienestar, salud, sostenibilidad o atención a los animales y su entorno, han apostado por disminuir sus ingestas de carne e incrementar en idéntica proporción la de sucedáneos vegetales".

Las posibilidades que brinda el mercado internacional es una oportunidad de incluir a los pequeños productores agrícolas, de manera que ellos sean parte de los beneficios. Como expone el Consejo Nacional de la Competitividad -CNC- (2014, p. 10) "el desarrollo del país y el bienestar de la población requieren que el crecimiento económico en los próximos años sea alto, constante y sostenido". El incremento de las exportaciones

Innova Market Insights Disponible en http://www.innovadatabase.com/ 
agrarias es un camino para lograrlo y en el deben aportar todos los sectores posibles. Como exponen Fort y Vargas $(2015$, p. 93) "podemos afirmar que los miembros de las organizaciones rurales de productores buscan, de diversas formas, mejorar su nivel de vida mediante la acción colectiva".

Pérez (2017, p. 2) en relación a la integración del pequeño agricultor expone las acciones que se están llevando y que, sin embargo, no logra consolidarse por las mismas limitaciones de los organismos que son responsables de la tarea y por las articulaciones que son necesarias para llevarlas a cabo:

El Estado tiene una política expresa para ello, pero me parece que el Minagri no posee la suficiente cantidad de instituciones (programas y proyectos) para lograrlo; por ejemplo, Agroideas, Sierra y Selva Exportadora, Agrorural no se dan abasto para que estas funciones se desconcentren territorialmente a la escala que el sector agrario lo requiere. Adicionalmente, creo que el Estado deberá mejorar sustancialmente la articulación productiva intersectorial (del sector agrario con los demás), lo cual permitirá mejorar los encadenamientos productivos en beneficios de la producción nacional.

En el caso de los pequeños agricultores de Lunahuaná, el 28,5\% considera que es "muy importante" y el 67,7 \% "importante" (anexo 2) el trabajo que están realizando las diversas instituciones del Estado en el valle, siendo la tarea más importante lo relacionado al financiamiento y conocimiento acerca de la exportación y los exportadores (anexo 2). Es en este ambiente de querer participar que el Estado se convierte en un agente dinámico de cambio, sino lo hace Perú seguirá teniendo un predominante comportamiento extractivista.

\section{CONCLUSIONES}

El crecimiento económico del Perú implica un compromiso con los pequeños agricultores, lo que hace necesario otorgarles las herramientas que les permitan integrarse a los mercados internacionales, siendo la capacitación, como un concepto amplio, uno de los más necesarios. A través de ella se debe buscar el incremento de la productividad de modo que permita generar el volumen de producción que posibilite identificar y diseñar oportunidades que fortalezcan la capacidad de negociación frente a compradores locales y en el extranjero. Son estas las actividades las que sirven como estímulo para fortalecer la actividad económica y sumar la preocupación por el medio ambiente en que habitan.

La economía global pone al descubierto necesidades que pueden ser satisfechas por los actuales productores, sin embargo, el crecimiento de la demanda internacional requiere de nuevos centros de producción, a la par que el incremento de la productividad. Los inversionistas en el sector agrícola, con experiencia en 
comercialización, necesitan una presentar una mayor oferta a sus compradores para poder mantener su confianza, siendo este el momento en que se debe aprovechar para integrar a los pequeños agricultores.

Los pequeños agricultores tienen un papel estratégico en la economía nacional, considerando su papel de abastecedores internos de alimentos. La principal desventaja que tienen es su poca integración, lo que se convierte en un desafío para el Estado y los propios inversionistas. Le corresponde al Estado diseñar la estrategia de integración de los productores a la cadena de exportación de modo que integre a los más posibles, proveyéndoles de los instrumentos que ellos mismos reconocen, son sus limitaciones: capacitación, financiamiento indirecto, entre otros.

El papel del Estado debe ser el de un agente dinámico que aglutine la capacidad de los exportadores para penetrar nuevos mercados internacionales, invirtiendo en infraestructura que disminuya sus costos externos adicionales, generando también un efecto multiplicador en las comunidades que están alrededor de los importantes centros de producción agrícola. En este proceso debe otorgar los suficientes incentivos que lleven a acercarse más a los pequeños productores además de lo que puede hacer la creciente demanda internacional.

\section{BIBLIOGRAFÍA}

Acemoglu, Daron y Robinson, James. (2012). Porqué fracasan los países: los orígenes del poder, la prosperidad y la pobreza. Bogotá: Planeta, 608 p.

Aranguri, Milagros. (2017). Asesora de capacitación empresarial de Promperú. Lima, 10 de noviembre de 2017.

Arteaga, William. (2016). Gestión del sector agricultura al 2021: hacia un desarrollo sostenible. En: Consorcio de Universidades. Metas del Perú al Bicentenario, Lima: Perú. p.35-44.

Asamblea General de Organización de las Naciones Unidas (2012). Resolución 66/222. Año Internacional de la agricultura familiar, 2014. Nueva York: Organización de las Naciones Unidas.

Casas, Andrés. (2017). Profesor investigador de la Universidad Nacional Agraria. 21 de abril del 2017.

Cienfuegos, Javiera. (2014). Tendencias familiares en América Latina: diferencias y entrelazamientos. En: Cepal. Notas de población. Santiago de Chile: Cepal, n 99, p. 11-38.

Comisión Económica para América Latina y el Caribe. Cepal. (2017). Perspectivas de la agricultura y el desarrollo rural en las Américas: una mirada hacia América Latina y el Caribe 2017 - 2018. San José: Cepal, FAO, IICA, 267 p.

Conferencia de las Naciones Unidas sobre Comercio y Desarrollo. Unctad. (2015). El papel de los pequeños agricultores en la producción y el comercio sostenibles de los productos básicos. Ginebra: Unctad, 20 p. 
Consejo Nacional de la Competitividad (2014). Agenda de competitividad 2014 - 2018, Rumbo al bicentenario. Lima, Perú: Ministerio de Economía y Finanzas, 146p.

Cotler, Pablo. (2017). La inclusión financiera en América Latina. En: Villarreal, Francisco. (Ed.), La inclusión financiera de pequeños productores rurales. Santiago de Chile: Cepal, p. 37-57.

Czinkota, Michael; Ronkainen, IIkka; Moffett, Michael y Ortiz, Manuel. (2007). Negocios internacionales. Ciudad de México: International Thomson, 779 p.

Daneshvar, Cameron; Garry, Sthepanie; López, Jesús; Santamaría, Jesús y Villarreal, Francisco. (2017). La inclusión financiera de pequeños productores rurales: tendencias y desafíos. En: Villarreal, Francisco (Ed.) La inclusión financiera de pequeños productores rurales . Santiago de Chile: Cepal, p. 15-29.

Daniels, Jonh; Radebaugh, Lee y Sullivan, Daniel. (2013). Negocios internacionales: ambientes y operaciones. Ciudad de México: Pearson Educación, 878 p.

Díez, Ramón. (2017). Secretario Administrativo de la Universidad Nacional Agraria La Molina, Lima, Perú. 24 de abril, 2017

Fort, Ricardo y Vargas, Ricardo. (2015). Estrategias de articulación de los productores agrarios en la costa peruana ċasociatividad, vinculación con empresas o ambas? En: Escobar, Javier, Ricardo Ford y Zegarra, Eduardo. (Eds.), Agricultura Peruana: nuevas miradas desde el censo agropecuario. Lima: Grade, p. 87-108.

Hill, Charles. (2011). Negocios internacionales: competencia en el mercado global. 8.a ed. Ciudad de México: McGraw Hill, 703 p.

Instituto Nacional de Estadística e Informática. INEI. (2017).Cuentas Nacionales1950 -2016. Lima, Perú: INEI.

León, Janina. (2018). Inclusión financiera de las microempresas y las pequeñas y medianas empresas en el Perú: el caso de la banca de desarrollo. En: Pérez, Esteban y Titelman, Daniel. (Eds), La inclusión financiera para la inserción productiva y el papel de la banca de desarrollo. Santiago de Chile, Cepal. p. 189-220.

Magallanes, Juan. (2017). Director del Departamento de Economía de la Universidad Nacional de La Molina. 1 de diciembre de 2017.

Maletta, Héctor. (2017). La pequeña agricultura familiar en el Perú, una tipología microrregionalizada. Lima: Organización de las Naciones Unidas para la Alimentación y la Agricultura, 208 p.

Ministerio de Agricultura y Riego. Minagri. (2015a). Estrategia nacional de agricultura familiar 2015 -2021. Lima: Minagri.

Ministerio de Agricultura y Riego. Minagri. (2015b). Plan estratégico sectorial multianual 2015 2021. Lima: Minagri.

Ministerio de Agricultura y Riego. Minagri. (2016). Política nacional agraria. Lima: Minagri.

Ministerio de Agricultura y Riego. (2017). Evaluación anual del plan estratégico sectorial multianual PESEM 2015 - 2021 correspondiente al año 2016. Lima: Minagri.

Murcia, José Luis. (2016). La preocupación por la salud y la curiosidad marcan tendencia en la 
alimentación. En: Revista Distribución y consumo. n.o141, p. 16 - 21.

Ocaña, Nora. (2017). Directora de la Dirección de Seguimiento y Evaluación de Políticas (Minagri). 13 de noviembre de 2017.

Oddone, Nahuel y Padilla, Ramón. (2017). Fortalecimiento de cadenas de valor rurales. Santiago de Chile: Cepal, 444 p.

Pérez, Esteban y Titelman, Daniel. (2018). La banca de desarrollo y la innovación para la inclusión financiera. En: La inclusión financiera para la inserción productiva y el papel de la banca de desarrollo. Santiago de Chile: Cepal, p. 59-78.

Pérez, Silvia. (2017). Profesora investigadora, Universidad Nacional Agraria. Lima, 1 de diciembre de 2017.

Porter, Michael. (2009). Ser competitivo. 6.a ed. Barcelona: Deusto, 624 p.

Quiroz, Verónica. (2017). Desafíos en materia de desarrollo productivo en el espacio rural de Centroamérica y la República Dominicana. En: Padilla, Ramón. (Ed.) Política industrial rural y fortalecimiento de cadenas de valor. Santiago de Chile: Cepal, p 25-68.

Salas, Vania. (2015). El rol de la asociatividad en la participación comercial de los productores agrarios: El caso de Piura. Lima: Consorcio de Investigación. 39 p. 


\section{ANEXO 1 \\ CUESTIONARIO CUALITATIVO. LAS ACCIONES NECESARIAS PARA INTEGRAR AL PEQUEÑO AGRICULTOR A LA CADENA DE EXPORTACIONES EN PERÚ}

Buenos días (tardes). Mi nombre es y estamos realizando una investigación acerca de la integración del pequeño agricultor a la cadena de exportaciones. Usted es una persona que se dedica a esta actividad y tiene la suficiente experiencia para brindarnos valiosa información. Nos gustaría hacerle las siguientes preguntas. (E. Explicar al entrevistado que será grabado. Tener lista la grabadora. En caso de entrevista por internet escribe sobre la línea)

\section{Tema 1. Papel de la producción agraria en la estrategia del PNDP}

1.1 ¿Qué tan importante es la agricultura en la economía peruana? ¿Qué beneficios le otorga al país?

1.2 ¿Es conveniente que en el Perú se produzcan con mayor énfasis productos agrarios y se les dé mayor valor agregado? (E. Entrevistado explica sus razones. Motivarlo a que detalle)

1.3 ¿Qué tan importante es que la producción agraria peruana se oriente al mercado internacional? ¿Afecta de alguna manera la producción para consumo doméstico?

1.4 Puntualmente ¿Cuáles considera que serán los efectos de la producción y el comercio de los productos agrarios en el mercado internacional para nuestro país? (E. Hasta dos respuestas. Mostrar tabla 1)

a. Incremento de cantidad de ha dedicadas a la producción agraria

b. Mayor inversión nacional y extranjera

c. Incremento de divisas por exportación

d. Impacto en otras industrias (proveedores de servicios)

e. Cambios relativos en la matriz de producción

f. Ingreso a industrias de mayor valor agregado

g. Otros: 
1.5 Aparte de los beneficios citados anteriormente ¿considera que se originarán beneficios en las otras industrias locales? (E. Entrevistado explica los beneficios. Motivarlo a que detalle)

1.6 ¿Considera que las empresas proveedoras de servicios a la industria agraria está en condiciones de apoyar la cadena de abastecimiento y distribución de los productores?
a. Sí
( ) (E. Solicitar explique sus razones)
b. No
( ) (E. Solicitar explique sus razones)

1.7 La diversificación agraria debe ser:
a. Política de Estado
b. El inversionista lo decide
c. Un acuerdo entre el Estado y los inversionistas

Tema 2. El Estado y los inversionistas privados en la estrategia del PNDP

2.1 Si lo conociera cel actual Marco Legal es suficiente para promover la mayor producción agraria?
a. Sí
( ) (E. Si la respuesta es sí pasar a pregunta 16)
b. No
( ) (E. Pasar a pregunta 1.5)

2.2 Si lo conociera ¿Qué le falta al actual Marco legal respecto a la estrategia de diversificación productiva? (E. Entrevistado explica sus razones. Motivarlo a que detalle)

2.3 ¿Qué expectativas se tiene respecto a la estrategia de diversificación productiva promovida por el Ministerio de la Producción en el sector agrario? (E. Entrevistado explica sus razones. Motivarlo a que detalle)

2.4 ¿Qué tan importante es el papel del Estado en el proceso de diversificación productiva?

2.5 Considerando que la estrategia de diversificación productiva es un proceso de largo aliento, ¿Cuánto estaría interesado el inversionista en participar? 
2.5 ¿Qué barreras, publicas y privadas, puede haber para que la estrategia de diversificación productiva se desarrolle?

2.6 ¿Cuáles son las principales acciones que deben realizar el Estado y los inversionistas privados para incentivar a los inversionistas a participar en la estrategia de diversificación productiva? (E. Hasta dos respuestas, mostrar tabla 2)

a. Identificación de los lugares en donde debe mejorar la infraestructura de riego

b. Potenciar Agrobanco para que financie grandes proyectos agrícolas

c. Emisión de bonos soberanos para recursos de apoyo a la agricultura

d. Comprometer a los inversionistas privados de apoyo a las pymes relacionadas

e. Devaluar la moneda nacional y mejorar el precio de la divisa extranjera ( )

f. Otorgar incentivos para que se otorgue mayor valor agregado

g. Crear instituciones educativas relacionadas para mejora de la productividad

h. Otros:

\section{Tema 3. El valor agregado en la producción agraria}

3.1 En su opinión ¿Qué efectos tiene la producción agraria en la matriz de producción local en el largo plazo? (E. Mostrar tabla 2)

a. No tiene ningún efecto

b. Modifica poco la matriz de producción

c. Modifica de manera regular la matriz de producción

d. Modifica significativamente la matriz de producción

3.2 ¿Cuál es su opinión respecto a que la producción agrícola exportable se concentre en la de tipo industrial (caña de azúcar, soya, azúcar, maíz) o alimentario (frutas y vegetales: palta, espárrago, mango, uvas)? (E. Explicar razones)

3.3 ¿Qué tan importante es que la producción agraria local exportable se le otorgue un mayor valor agregado? (E. Explicar razones)

3.4 ¿Cuáles son los productos agrarios peruanos exportables a los que se les debe dar mayor valor agregado? (E. Explicar razones) 
3.5 ¿Cuáles son los productos agrarios peruanos exportables que no es necesario que se les otorgue mayor valor agregado? (E. Explicar razones)

3.6 ¿Cuáles nuevos productos agrarios que tienen potencial en el mercado internacional deben introducirse en la producción local para luego exportar?

3.7 ¿Cómo incluir a los medianos y pequeños agricultores en este proceso?

\section{DATOS DEL ENTREVISTADO}

Nombre: Teléfono:

Cel.: Empresa / organización:

Cargo:

Dirección-e: Distrito:

\section{DATOS DE CONTROL INTERNO}

Entrevistador: Código:

Fecha: Hora de inicio de la entrevista:

Hora de fin de la entrevista:

Muchas gracias 
ANEXO 2.

\section{CUESTIONARIO CUANTITATIVO. LAS ACCIONES NECESARIAS PARA INTEGRAR AL PEQUEÑO AGRICULTOR A LA CADENA DE EXPORTACIONES EN EL PERÚ}

Buenos días (tardes). Mi nombre es $\mathrm{y}$ estamos realizando una investigación acerca de la integración del pequeño agricultor a la cadena de exportaciones. Usted es una persona que se dedica a esta actividad y tiene la suficiente experiencia para brindarnos valiosa información. Nos gustaría hacerle las siguientes preguntas:

Pregunta previa:

a) ¿Es usted exportador de su producción agraria?

Sí ( ) No ( ) (E. Si menciona sí, dar las gracias).

b) ¿Le agradaría que su producción agrícola se exporte?

Sí ( ) No ( ) (E.: Si responde no, dar las gracias).

c) ¿Tiene la suficiente producción para integrarse a una cadena de exportación?

Sí ( ) No ( ) (E. Aplicar el cuestionario)

Tema 1. Acciones necesarias para integrar al pequeño agricultor a la cadena de exportaciones

1.1 ¿Qué tan importante es para usted que su producción agrícola se exporte?

1.1.1. Muy Importante

1.1.2. Importante

1.1.3 Me es indiferente

1.1.4 Poco importante

1.1.5 Nada importante

1.2 ¿Está dispuesto a formar parte de una asociación de productores (por ejemplo, cooperativas agrarias) para exportar su producción?
1.2.1 Sí
1.2.2 No 
1.3 ¿Está dispuesto a vender su producción exportable a una organización que tiene experiencia en los negocios internacionales?

\subsubsection{Sí}

1.3.2 No

1.4 ¿Tiene conocimiento de que para exportar la producción tiene que adecuarse a los estándares que establecen los compradores extranjeros?

\subsubsection{Sí}

\subsubsection{No}

1.5 ¿Qué beneficios puede obtener el exportador experimentado si decide asociarlo como su proveedor de productos que van al mercado internacional?

1.5.1 Me sujeto a los estándares internacionales de producción

1.5.2 Me capacito más en tecnología de exportación

1.5.3 Firmo una carta de compromiso de provisión por largo plazo

1.5.4 Promuevo la idea de exportación en otros agricultores del valle

1.5.5 Identifico las actividades para aumentar mi producción

1.5.6 Lo apoyo en buscar nuevos proveedores en mi comunidad

1.5.7 Otros:

1.6 ¿Qué tanto se comprometería con su producción para exportación?

1.6.1 Compromiso total

1.6.2 Me comprometo

1.6.3 Depende las circunstancias

1.6.4 No me comprometo

1.6.5 No asumo un compromiso total

1.7 ¿Qué acciones considera necesarias que deben realizar el Estado y los exportadores para su incorporación a la cadena de exportación?

1.7.1 Que me brinde capacitación para mejorar producción

1.7.2 Se me otorgue financiamiento para la campaña

1.7.3 Ninguna. Que me dejen producir y solo entrego resultados

1.7.4 Conocer nueva tecnología para producir

1.7.5 Que me hagan conocer sus procesos de producción

1.7.6 Conocer acerca de otras experiencias exitosas

\subsubsection{Otros:}




\section{Tema 2. Actividades de los grandes agricultores exportadores en relación a los pequeños agricultores}

2.1 ¿Tiene información de exportadores que hay en el valle?

2.1.1 Abundante información

2.1.2 Lo que todos saben

2.1.3 A veces me preocupo en saber

2.1.4 Conozco poco

2.1.5 No sé nada

2.2 En su opinión, ¿qué compromisos debe asumir el exportador respecto a usted y su producción exportable?

2.1.1 Otorgarme los precios justos

2.1.2 Apoyarme para que aprenda de nueva tecnología de producción

2.1.3 Acercarme a las instituciones financieras para tener menor costo financiero

2.1.4 Apoyarme capacitándome en tecnología de producción

2.1.5 Brindarme información acerca de cómo va el mercado

2.1.6 Que me otorgue financiamiento a mi producción

2.1.7 Otros:

2.3 ¿Qué opinión tiene de los exportadores que hay en el valle?

2.3.1 Muy favorable. Ayudan a la gente y están buscando que nos integremos

2.3.2 Favorable. Se portan bien y dan trabajo eventual

2.3.3 Me es indiferente. No presto atención a lo que hacen

2.3.4 Nada favorable. Hacen poco por el lugar y así no es

2.3.5 Muy desfavorable. No hacen nada por el lugar, todo se lo llevan

2.4 Si el exportador le dice que debe cambiar de cultivo ¿Cómo reaccionaría usted?

2.4.1 No tengo problemas. Lo acepto sin objeción

2.4.2 Lo acepto, pero un ingreso por mientras dure el cambio

2.4.3 Tengo que consultarlo con mi familia y otros conocidos 
2.4.4 No me comprometo con el cambio

2.4.5 Si todos los pequeños agricultores lo aceptan, yo también

\subsubsection{Otros:}

2.5 Cite cinco productos agrícolas que se exportan desde el valle:

a.

b.

c.

d.

e.

2.6 ¿Que otros productos deberían producirse en el valle para la exportación?
a.
b.
c.
d.
e.

\section{Tema 3. Las actividades del Estado en relación a los pequeños agricultores}

3.1 ¿Considera usted que el papel que está realizando el Estado a través de sus diversas instituciones entre los agricultores del Valle es?

3.1.1 Muy importante

3.1.2 Importante

3.1.3 Da igual

3.1.4 Poco importante

3.1.5 Nada importante

3.2 Mencione, en específico la organización del Estado que lo apoya: y en qué actividades:

3.2.1 Financiamiento o fuentes de financiamiento

3.2.2 Semillas y proveedores

3.2.3 Cultura: saber todo el proceso de producción hasta exportación 
3.2.4 Conocimiento acerca de la exportación y exportadores

3.2.5 Uso de la tecnología de riego

3.2.6 Cómo relacionarse con exportadores

3.2.7 Condiciones que debo tener para ser parte de una cadena de exportación

\subsubsection{Otros}

3.3 ¿En qué nuevas actividades debería apoyarlo las organizaciones del Estado que en la actualidad participan con usted
a.
b.
C.
d.
e.

3.4 ¿Considera oportuno que los pequeños agricultores formen una asociación para dedicarse a la agroexportación con el apoyo de organizaciones del Estado (ministerios u otros)?
3.4.1 Sí
3.4.2 No
( )

\section{DATOS DEL ENTREVISTADO}

Nombre: Teléfono:

Cel.: Empresa / organización:

Cargo:

Dirección-e: Distrito:

\section{DATOS DE CONTROL INTERNO}

Entrevistador: Código:

Fecha: Hora de inicio de la entrevista:

Hora de fin de la entrevista:

Muchas gracias 


\section{ANEXO 3. RESULTADOS DE APLICACIÓN DEL CUESTIONARIO CUANTITATIVO}

\section{Tema 1. Acciones necesarias para integrar al pequeño agricultor a la cadena de exportaciones}

1.1 ¿Qué tan importante para usted que su producción agrícola se exporte?

\begin{tabular}{clc}
\hline Código & \multicolumn{1}{c}{$\begin{array}{c}\text { Importancia de que su producción } \\
\text { agrícola se exporte }\end{array}$} & Porcentaje \\
\hline 1.1 .1 & Muy importante & 61,5 \\
\hline 1.1 .2 & Importante & 38,5 \\
\hline 1.1 .3 & Me es indiferente & 0 \\
\hline 1.1 .4 & Poco importante & 0 \\
\hline 1.1 .5 & Nada importante & 0 \\
\hline
\end{tabular}

1.2 ¿Está dispuesto a formar parte de una asociación de productores (por ejemplo, cooperativas agrarias) para exportar su producción?

\begin{tabular}{ccc}
\hline Código & $\begin{array}{c}\text { A favor de formar parte de una asociación } \\
\text { de productores }\end{array}$ & Porcentaje \\
\hline 1.2 .1 & $\mathrm{Si}$ & 92,3 \\
\hline 1.2 .2 & $\mathrm{No}$ & 7,7 \\
\hline
\end{tabular}

1.3 ¿Está dispuesto a vender su producción exportable a una organización que tiene experiencia en los negocios internacionales?

\begin{tabular}{ccc}
\hline Código & $\begin{array}{c}\text { Disposición de vender su producción } \\
\text { exportable }\end{array}$ & Porcentaje \\
\hline 1.3 .1 & Sí & 90,8 \\
\hline 1.3 .2 & No & 9,2 \\
\hline
\end{tabular}

1.4 ¿Tiene conocimiento de que para exportar la producción tiene que adecuarse a los estándares que establecen los compradores extranjeros?

\begin{tabular}{ccc}
\hline Código & Adecuación a los estándares de exportación & Porcentaje \\
\hline 1.4 .1 & Sí & 86,1 \\
\hline 1.4 .2 & No & 13,9 \\
\hline
\end{tabular}


1.5 ¿Qué beneficios puede obtener el exportador experimentado si decide asociarlo como su proveedor de productos que van al mercado internacional? (E: Hasta dos respuestas)

\begin{tabular}{clc}
\hline Código & Beneficios que se espera obtener del exportador experimentado & Porcentaje \\
\hline 1.5 .1 & Me sujeto a los estándares & 34,6 \\
\hline 1.5 .2 & Me capacito en tecnología & 49,2 \\
\hline 1.5 .3 & Firmo una carta de compromiso & 41,5 \\
\hline 1.5 .4 & Promuevo la idea de exportación & 41,5 \\
\hline 1.5 .5 & Aumentar mi producción & 30,8 \\
\hline 1.5 .6 & $\begin{array}{l}\text { Lo apoyo en buscar nuevos proveedores en mi comur } \\
\text { nidad }\end{array}$ & 0,0 \\
\hline 1.5 .7 & Otros & 0,0 \\
\hline
\end{tabular}

1.6 ¿Qué tanto se comprometería con su producción para exportación?

\begin{tabular}{clc}
\hline Código & Compromiso del pequeño agricultor con la exportación & Porcentaje \\
\hline 1.6 .1 & Compromiso total & 30,8 \\
\hline 1.6 .2 & Me comprometo & 21,5 \\
\hline 1.6 .3 & Depende las circunstancias & 39,2 \\
\hline 1.6 .4 & No me comprometo & 0,0 \\
\hline 1.6 .5 & No asumo un compromiso total & 8,5 \\
\hline
\end{tabular}

1.7 ¿Qué acciones considera necesarias que debe realizar el Estado y los exportadores para su incorporación a la cadena de exportación? (E. Hasta dos respuestas)

\begin{tabular}{clc}
\hline Código & \multicolumn{1}{c}{ Acciones necesarias } & Porcentaje \\
\hline 1.7 .1 & Capacitación para mejorar producción & 69,2 \\
\hline 1.7 .2 & Financiamiento para la campaña & 43,1 \\
\hline 1.7 .3 & Ninguna. Dejen producir y ver resultados & 13,1 \\
\hline 1.7 .4 & Nueva tecnología para producir & 23,8 \\
\hline 1.7 .5 & Conocer procesos de producción & 20,0 \\
\hline 1.7 .6 & Conocer experiencias exitosas & 19,2 \\
\hline 1.7 .7 & Otros & 0,0 \\
\hline
\end{tabular}


Tema 2. Actividades de los grandes agricultores exportadores en relación a los pequeños agricultores

2.1 ¿Tiene información de exportadores que hay en el valle?

\begin{tabular}{clc}
\hline Código & \multicolumn{1}{c}{ Información acerca de los exportadores del valle } & Porcentaje \\
\hline 2.1 .1 & Abundante información & 7,7 \\
\hline 2.1 .2 & Lo que todos saben & 11,5 \\
\hline 2.1 .3 & Me preocupo por saber & 19,2 \\
\hline 2.1 .4 & Conozco poco & 46,2 \\
\hline 2.1 .5 & No sé nada & 15,4 \\
\hline
\end{tabular}

2.2 En su opinión, ¿̇qué compromisos debe asumir el exportador respecto a usted y su producción exportable? (E. Hasta dos respuestas)

\begin{tabular}{clc}
\hline Código & \multicolumn{1}{c}{$\begin{array}{c}\text { Compromisos que debe asumir el exportador respecto al } \\
\text { pequeño productor }\end{array}$} & Porcentaje \\
\hline 2.2 .1 & Precios justos & 73,1 \\
\hline 2.2 .2 & Apoyo para aprender nueva tecnología & 65,4 \\
\hline 2.2 .3 & $\begin{array}{l}\text { Apoyarme en buscar créditos a menor costo } \\
\text { financiero }\end{array}$ & 23,1 \\
\hline 2.2 .4 & Capacitación en tecnología de producción & 34,6 \\
\hline 2.2 .5 & Información acerca de cómo va el mercado & 26,9 \\
\hline 2.2 .6 & Otorgue financiamiento a la producción & 42,3 \\
\hline 2.2 .7 & Otros & \\
\hline
\end{tabular}

2.3 ¿Qué opinión tiene de los exportadores que hay en el valle?

\begin{tabular}{clc}
\hline Código & Opinión acerca de los exportadores & Porcentaje \\
\hline 2.3 .1 & Muy favorable. Ayudan a la gente & 14,6 \\
\hline 2.3 .2 & Favorable. Se portan bien & 53,8 \\
\hline 2.3 .3 & Me es indiferente. No presto & 6,2 \\
\hline 2.3 .4 & Nada favorable. Hacen poco & 4,6 \\
\hline 2.3 .5 & Muy desfavorable. No hacen nada & 9,3 \\
\hline No respondieron & & 11,5 \\
\hline
\end{tabular}


2.4 Si el exportador le dice que debe cambiar de cultivo ¿Cómo reaccionaría usted? (E. Hasta dos respuestas)

\begin{tabular}{clc}
\hline Código & \multicolumn{1}{c}{ Cambiar de cultivo } & Porcentaje \\
\hline 2.4 .1 & Lo acepto sin objeción & 23,1 \\
\hline 2.4 .2 & Lo acepto, pero es necesario un ingreso & 43,1 \\
\hline 2.4 .3 & Tengo que consultarlo & 13,1 \\
\hline 2.4 .4 & No me comprometo & 10,0 \\
\hline 2.4 .5 & Si todos los pequeños agricultores lo aceptan & 19,2 \\
\hline 2.4 .6 & Otros & 0 \\
\hline
\end{tabular}

2.5 Cite cinco productos agrícolas que se exportan desde el valle

\begin{tabular}{lcc}
\hline $\begin{array}{c}\text { Producto agrícola } \\
\text { exportable }\end{array}$ & $\begin{array}{c}\text { Conocimiento de los productos que se exportan en el } \\
\text { valle }\end{array}$ & Porcentaje \\
\hline Maíz & 15 & 11,5 \\
\hline Mandarina & 45 & 34,6 \\
\hline Ají amarillo & 12 & 9,2 \\
\hline Mango & 6 & 4,6 \\
\hline Granada & 8 & 6,1 \\
\hline Palta & 56 & 43,1 \\
\hline Maíz morado & 13 & 10,0 \\
\hline Uva & 25 & 19,2 \\
\hline Arándano & 35 & 26,9 \\
\hline Cítricos & 12 & 9,2 \\
\hline Pisco & 28 & 21,5 \\
\hline Vino & 45 & 34,6 \\
\hline No respondió & 23 & 17,7 \\
\hline
\end{tabular}


Pedro Barrientos Felipa

Tema 3. Las actividades del estado en relación a los pequeños agricultores

3.1 ¿Considera usted que el papel que está realizando el Estado a través de sus diversas instituciones entre los agricultores del valle es?

\begin{tabular}{clc}
\hline Código & \multicolumn{1}{c}{ Papel que realiza el Estado } & Porcentaje \\
\hline 3.1 .1 & Muy importante & 28,5 \\
\hline 3.1 .2 & Importante & 67,7 \\
\hline 3.1 .3 & Da igual & 0,0 \\
\hline 3.1 .4 & Poco importante & 3,8 \\
\hline 3.1 .5 & Nada importante & 0,0 \\
\hline
\end{tabular}

3.2 Mencione, en específico la organización del Estado que lo apoya: y en qué actividades:

\begin{tabular}{clc}
\hline Código & \multicolumn{1}{c}{ Actividades en las que apoya el Estado } & Porcentaje \\
\hline 3.2 .1 & Financiamiento o fuentes de financiamiento & 17,7 \\
\hline 3.2 .2 & Semillas y proveedores & 6,9 \\
\hline 3.2 .3 & $\begin{array}{l}\text { Cultura: saber todo el proceso de producción } \\
\text { hasta exportación }\end{array}$ & 3,2 \\
\hline 3.2 .4 & $\begin{array}{l}\text { Conocimiento acerca de la exportación y } \\
\text { exportadores }\end{array}$ & 11,5 \\
\hline 3.2 .5 & Uso de la tecnología de riego & 3,8 \\
\hline 3.2 .6 & Cómo relacionarse con exportadores & 0,6 \\
\hline 3.2 .7 & $\begin{array}{l}\text { Condiciones que debo tener para ser parte de } \\
\text { una cadena de exportación }\end{array}$ & 52,3 \\
\hline No respondió & Otros & \\
\hline
\end{tabular}

3.3 ¿En qué nuevas actividades debería apoyarlo las organizaciones del Estado que en la actualidad participan con usted? (E. Hasta cinco repuestas)

\begin{tabular}{lcc}
\hline \multicolumn{1}{c}{ Actividades en las que debería apoyar el Estado } & Porcentaje \\
\hline Capacitación & 65 & 50,0 \\
\hline Financiamiento & 43 & 33,1 \\
\hline Plantas & 32 & 24,6 \\
\hline Abonos & 30 & 23,1 \\
\hline Semillas & 28 & 21,5 \\
\hline Tecnología & 12 & 9,2 \\
\hline Otros & 4 & 3,1 \\
\hline
\end{tabular}


3.4 ¿Considera oportuno que los pequeños agricultores formen una asociación para dedicarse a la agroexportación con el apoyo de organizaciones del Estado (ministerios u otros)?

\begin{tabular}{ccc}
\hline Código & $\begin{array}{c}\text { Oportunidad de formar asociaciones con apoyo } \\
\text { del Estado }\end{array}$ & Porcentaje \\
\hline 3.4 .1 & Sí & 98,5 \\
\hline 3.4 .2 & No & 1,5 \\
\hline
\end{tabular}

